\title{
Orientações morfológicas para a aplicação de toxina botulínica para o tratamento de bruxismo e hipertrofia do músculo masseter.
}

\author{
Nicolas Muhlegger*, Paulo H. F. Caria.
}

\section{Resumo}

O músculo masseter tem importância clínica pois é o foco de desordens como hipertrofia massetérica, bruxismo e disfunções temporomandibulares (DTM). Há diferentes formas de tratar essas patologias, porém, a remissão de sintomas como dor muscular e rigidez da mandíbula apresentaram resultados positivos com o uso da toxina botulínica (TXB-A). Entretanto, falhas na execução da técnica pelo desconhecimento da anatomia do músculo masseter e presença de estruturas anatômicas adjacentes, levaram a resultados insatisfatórios.

Palavras-chave: Toxina botulínica, músculo masseter, bruxismo, odontologia.

\section{Introdução}

O bruxismo é uma atividade muscular mastigatória repetitiva caracterizada pelo apertamento ou moagem dos dentes e/ou com movimentação da mandíbula que pode ocorrer durante o dia ou a noite, durante o sono. Seu tratamento é plural, exigindo diferentes avaliações e abordagens.

Objetivo: Fornecer diretrizes anatômicas da região do músculo masseter para proporcionar maior sucesso na aplicação da TXB-A e evitar acidentes no local. Materiais e métodos: Foram realizadas 5 análises em 57 hemifaces de cadáveres do Depto. de Morfologia da FOP/UNICAMP. 1 ${ }^{a}$ ) D1- Distância entre o ramo marginal da mandíbula do nervo facial e a margem inferior da mandíbula. $2^{2}$ ) D2 - Distância da margem anterior do músculo masseter até o ponto de saída do nervo facial da glândula parótida. 3aㅡ) D3 - Distância entre a parte mais anterior da glândula parótida e a borda anterior do músculo masseter. 4 ${ }^{a}$ ) Posição do ducto parotídeo, avaliada em relação à linha imaginária que conecta o tragus à comissura labial. 5a ) Recobrimento do masseter pela glândula parótida, foi avaliado dividindo-se o músculo em áreas (I a VIII). Todas as medidas foram realizadas em triplicata (ICC) com o auxílio de um paquímetro digital.

\section{Resultados e Discussão}

O ramo marginal da mandíbula do nervo facial passou sobre a superfície do músculo masseter em todos os espécimes avaliados nesse estudo. A distância média entre o ramo marginal da mandíbula do nervo facial e a margem inferior da mandíbula (D1) foi: $4.76 \pm 3.2 \mathrm{~mm}$ (média $\pm \mathrm{DP})$, com intervalo de $(0.96 \pm 10.1)$.

A distância da margem anterior do músculo masseter até o ponto de saída do nervo facial da glândula parótida (D2) foi: $7.2 \pm 4.73 \mathrm{~mm}$, com intervalo de $(1,6$ a 12,8mm) em 20 espécimes avaliadas.

Quanto a localização do ducto parotídeo em relação à linha virtual que conecta o tragus à comissura labial, foi classificado em 4 tipos: I - Acima da linha de referencia (23 casos de 55, 41,81\%), II - cruzando a linha de referência - de posterior para anterior $(19$ casos de 55 , $34,54 \%$ ), III - na linha de referencia (9 casos de 55, $16,36 \%)$, IV - abaixo da linha de referencia (4 casos de 55 , $7,27 \%)$.

Em relação aos compartimentos do músculo masseter recobertos pela glândula parótida, os mais comuns foram as áreas I e II (26 de 55 espécimes, 47,2\%).
Área I foi coberta pela glândula parótida em 12 casos $(21,8 \%)$, áreas I a III em 7 casos (12,7\%). As áreas I a IV foram cobertas pela glândula parótida em 5 casos $(9,0 \%)$ e área II em 3 casos (5,4\%). As áreas I e III; I, II e IV e I a IV e VI, 1 caso $(1,18 \%)$; as áreas I a VI foram cobertos pela glândula parótida em 1 caso $(1,18 \%)$.

As principais falhas no tratamento com TXB-A são a injeção na glândula parótida, $n$. marginal da mandíbula, $\mathrm{m}$. bucinador, artéria massetérica e veia facial, que acarretam insucesso ao tratamento e transtornos ao paciente e ao clínico.

No centro do compartimento $\mathrm{VI}$ do $\mathrm{m}$. masseter parece ser anatomicamente, o local mais seguro e eficiente de injeção de TXB-A, já que a glândula parótida geralmente ocupa os compartimentos I e II, e o ramo marginal da mandíbula do nervo facial estava localizado em média $7,4 \mathrm{~mm}$ acima da margem inferior da mandíbula. Além disso, o músculo masseter é inervado em suas porções mais profundas.

\section{Conclusões}

O ramo marginal da mandíbula do nervo facial, a base da mandíbula e a margem anterior do músculo masseter, sempre devem ser lembrados antes da aplicação da TXB-A no músculo masseter, devido à destacada proximidade que apresentam entre si. $\mathrm{O}$ ducto da glândula parótida ocupa, na maioria das vezes, o 1/3 superior do músculo masseter, portanto, essa região deve ser evitada; assim como o 2/4 posterior do mesmo músculo, devido a presença da glândula parótida.

Esses dados ajudam a determinar o local ideal para uma injeção eficaz e segura de toxina botulínica do tipo $A$ (TXB-A).

REFERÊNCIAS

1. Lobbezoo F, Ahlberg J, Glaros AG, Kato T, Koyano K, Lavigne GJ, de Leeuw R, Manfredini D, Svensson P, Winocur E (2013) Bruxism defined and graded: an international consensus. J Oral Rehabil 40(1):2-4.

2. Lavigne GJ, Huynh N, Kato T, Okura K, Adachi K, Yao D, Sessle B (2007) Genesis of sleep bruxism: motor and autonomic-cardiac interactions. Arch Oral Biol 52(4):381- 384

3. Manfredini D, Lobbezoo F (2010) Relationship between bruxism and temporomandibular disorders: a systematic review of literature from 1998 to 2008. Oral Surg Oral Med Oral Pathol Oral Radiol Endod 109(6):26-50.

4. Kato T, Dal-Fabbro C, Lavigne GJ (2003) Current knowledge on awake and sleep bruxism: overview. Alpha Omegan 96(2):24-32.

5. Lavigne G, Kato T (2005) Usual and unusual orofacial motor activities associated with tooth wear. Int J Prosthodont 18(4):291-292. 